\title{
Child protection in Scotland
}

The dental practitioner and child protection in Scotland

A. M. Cairns, J. Y. Q. Mok and R. R. Welbury Br Dent J 2005; 198: 517-520

\section{Objectives}

To identify from general dental practitioners: undergraduate and postgraduate training experience in child protection; numbers of suspected cases of child physical abuse; reasons for failing to report suspicious cases of child physical abuse; knowledge of local child protection protocols and procedures for referral.

\section{Materials and methods}

Postal questionnaires to 500 randomly selected general dental practitioners in Scotland, with a further 200 sent to a random sample of the original 500 to increase response rate.

Results

Sixty-one per cent (306) of the original 500 questionnaires, and 35\% (69) of the second random mail shot of 200 questionnaires were returned. Only 19\% could remember any undergraduate training and $16 \%$ had been to a postgraduate lecture or seminar in child protection. Twenty-nine per cent of dentists had seen at least one suspicious case in their career. Only 8\% of suspicious cases were referred on to the appropriate authorities. Reasons for failure to refer revealed that $11 \%$ were concerned about a negative impact on their practice, 34\% feared family violence towards the child, 31\% feared violence directed against them, and $48 \%$ feared litigation. Only $10 \%$ of dentists had been sent a copy of the local child protection guidelines on commencing work and only 15\% had seen their Area Child Protection Committee (ACPC) Guidelines via any route.

\section{Conclusions}

Due to lack of training or clear guidelines for dentists in Scotland, most practitioners were unsure what to do in the event of a suspicion of child abuse. Twenty-one per cent of dentists had encountered suspicious cases but failed to take any action. Dentists overwhelmingly requested appropriate training. This training should address dental competence in assessment of suspicious indicators and involve dentists in inter-agency child protection training.

\section{IN BRIEF}

- GDPs in Scotland are largely unaware of current child protection guidelines.

- Inadequate undergraduate and postgraduate training has resulted in significant barriers to referral to the child protection agencies.

- Future training should address the recognition of the signs of child abuse and knowledge of the both the pathways of referral and interagency working.

\section{COMMENT}

The report of the Victoria Climbié Inquiry' was highly critical of health professionals who, despite numerous contacts with Victoria and her family, failed to protect her and prevent her death at the hands of her carers. Published in 2003, it made recommendations about procedures and training for all agencies regularly in contact with children. Subsequent government documents have placed emphasis on early intervention to safeguard children yet child protection issues have received scant attention in the dental press and there has been little relevant UK-based dental research to date.

This study took the form of a postal questionnaire to general dental practitioners (GDPs) in Scotland in 2003. It addressed their training and experience in child protection, and asked about the perceived barriers to taking appropriate action when they had concerns about a child's welfare. Considering the sensitive and challenging issues addressed, there was an excellent response rate.

Surprisingly few respondents remembered any training on this topic. There was a discrepancy between the $29 \%$ of GDPs who had seen a case suspicious of abuse, and the $8 \%$ who had reported their concerns. It may be that these were clearly documented decisions after full consideration of the circumstances in discussion with senior colleagues, in line with current guidelines. ${ }^{2}$ However, this finding raises the uncomfortable question that dentists might have been able to intervene to save a child from continuing abuse, but failed to do so.

A number of concerns were reported which may have acted as barriers to dentists taking appropriate action. While concerns are understandable, in general those mentioned were based on misconceptions, or a 'mismatch' with the reality of present-day child protection practice, and would be allayed by appropriate and supportive training. In addition the authors identified a need to ensure that the responsible agencies do not overlook GDPs when local child protection guidelines are disseminated.

Since this study was completed, suitable training has become more widely available through postgraduate deaneries and a number of educational resources aimed specifically at the dental team are being developed. However, it remains the responsibility of individual GDPs to see that they and their staff take up training opportunities. It is encouraging that in this study $78 \%$ of respondents requested training, suggesting not only recognition of the need for change, but also willingness amongst Scottish dentists to respond to the challenge.

\section{J. C. Harris, Senior Community Dentist in Paediatric Dentistry, Rotherham PCT}

1. The Victoria Climbié Inquiry Report. London: The Stationary Office, 2003 Publication no. CM 5730. www.victoria-climbie-inquiry.org.uk

2. What to do if you're worried a child is being abused. Summary. London: Department of Health, 2003. Publication no. 31815.

doi: $10.1038 /$ sj.bdj.4812810 